\title{
HIGHLY PREVALENT HYPERURICAEMIA IS ASSOCIATED WITH ADVERSE CLINICAL OUTCOMES AMONG GHANAIAN STROKE PA- TIENTS: AN OBSERVATIONAL PROSPECTIVE STUDY
}

\author{
F. S. SARFO ${ }^{1,2}$, J. AKASSI ${ }^{1,2}$, N. K. B. ANTWI ${ }^{2}$, V. OBESE ${ }^{2}$, S. ADAMU $^{2}$, A. AKPALU ${ }^{3}$ and G. \\ BEDU-ADDO ${ }^{1,2}$ \\ ${ }^{1}$ Kwame Nkrumah University of Science and Technology, Kumasi, Ghana, ${ }^{2}$ Komfo Anokye Teaching Hospi- \\ tal, Kumasi, Ghana, ${ }^{3}$ Korle-Bu Teaching Hospital, Accra, Ghana
}

DOI: http://dx.doi.org/10.4314/gmj.v49i3.7

Corresponding author: Dr. Fred Stephen Sarfo

Conflict of Interest: None declared

\section{SUMMARY}

Background: Although a direct causal relationship between hyperuricaemia and stroke continues to be debated, strong associations between serum uric acid (SUA) and cerebrovascular disease exist. Very few studies have been conducted to evaluate the frequency and association between this potentially modifiable biomarker of vascular risk and stroke in sub-Saharan Africa. Therefore the aim of this study was to examine the association between hyperuricaemia and the traditional risk factors and the outcomes of stroke in Ghanaian patients.

Methods: In this prospective observational study, 147 patients presenting with stroke at a tertiary referral centre in Ghana were consecutively recruited. Patients were screened for vascular risk factors and SUA concentrations measured after an overnight fast. Associations between hyperuricaemia and stroke outcomes were analysed using Kaplan-Meier and Cox proportional hazards regression analysis.

Results: The frequency of hyperuricaemia among Ghanaian stroke patients was $46.3 \%$. Non-significant associations were observed between hyperuricaemia and the traditional risk factors of stroke. SUA concentration was positively correlated with stroke severity and associated with early mortality after an acute stroke with unadjusted hazards ratio of 2.3 (1.4 - 4.2, $\mathrm{p}=0.001$ ). A potent and independent dose-response association between increasing SUA concentration and hazard of mortality was found on Cox proportional hazards regression, aHR (95\% CI) of 1.65 (1.14-2.39), $\mathrm{p}=0.009$ for each $100 \mu \mathrm{mol} / \mathrm{l}$ increase in SUA.

Conclusions: Hyperuricaemia is highly frequent and associated with adverse functional outcomes among Ghanaian stroke patients. Further studies are warranted to determine whether reducing SUA levels after a stroke would be beneficial within our setting.

Key words: Hyperuricaemia, stroke, mortality, Ghana
E-mail: stephensarfo78@gmail.com

\section{INTRODUCTION}

Hyperuricaemia is an emerging risk factor associated with increased cardiovascular and cerebrovascular diseases (CVD). ${ }^{1}$ This is rather paradoxical because invivo and in-vitro studies have demonstrated uric acid to be a powerful free radical scavenger and its antioxidant properties would be expected to provide a number of benefits within the cardiovascular system. ${ }^{2}$ In contrast however, hyperuricaemia is linked with multiple proatherogenic processes, including increased oxidative stress $^{3,4}$, vascular smooth muscle cell proliferation ${ }^{5}$, and leukocyte activation. ${ }^{6}$

There is also evidence suggesting strong associations between hyperuricaemia and obesity ${ }^{7}$, hypertension ${ }^{8}$, reduced HDL cholesterol $^{9}$, hypertriglyceridaemia ${ }^{10}$, hyperinsulinaemia and reduced insulin sensitivity. 11,12 Therefore, it is unclear whether high serum uric acid promotes or protects against the development of CVD, or simply acts as a passive marker of increased risk.

In particular reference to the role of hyperuricaemia in stroke, it has been noted that serum uric acid is an independent predictor of stroke ${ }^{13,14}$ and two large studies have shown that serum uric acid independently predicts poor outcome in stroke patients. ${ }^{15,16}$ However, Chamorro et al found that among patients with acute ischaemic stroke, there was a $12 \%$ increase in the odds of a good clinical outcome for each milligram per deciliter increase of serum uric acid. Their finding indicated that in ischaemic stroke, the increased anti-oxidant effects of serum uric acid might mitigate damage. ${ }^{17}$

A meta-analysis of a total of 16 studies involving 238,449 adults revealed however that hyperuricaemia was associated with a significantly higher risk of both stroke incidence and mortality. 
It was concluded that hyperuricaemia may modestly increase the risks of both stroke incidence and mortality and that further studies were needed to determine whether lowering uric acid level may have any beneficial effects on stroke. ${ }^{18}$

Data on the associations between hyperuricaemia and stroke are sorely lacking in sub-Saharan Africa where stroke incidence, prevalence, morbidity and mortality are on the ascendency. ${ }^{19}$ This study therefore sought to evaluate the frequency of hyperuricaemia and its associations with the traditional risk factors of stroke as well as in-patient outcomes in a tertiary referral hospital in the middle belt of Ghana, West Africa.

\section{METHODS}

The Committee on Human Research Publications and Ethics at the Komfo Anokye Teaching Hospital (KATH) and Kwame Nkrumah University of Science and Technology approved this study. One hundred and forty-seven participants with case definition of stroke had uric acid measured on admission and were included in this observational prospective study.

Written informed consent was obtained either from conscious patients or their first- degree relatives when patients had reduced level of consciousness or aphasic. Patient's socio-demographic information, history and clinical examination findings with emphasis on cardiovascular risk factors for stroke and functional outcomes were captured on a study questionnaire.

The following definitions and techniques were used to identify risk factors for stroke in each subject:

Hypertension was defined as systolic blood pressure $\geq$ $140 \mathrm{~mm} \mathrm{Hg}$ or diastolic pressure $\geq 90 \mathrm{~mm} \mathrm{Hg}$ persisting $>7$ days after the acute event (World Health Organisation classification) or pre-stroke treatment with antihypertensive drugs. ${ }^{20}$

Diabetes mellitus was defined as a previous diagnosis of type I or II diabetes, at least 2 random blood glucose readings of $\geq 11.1 \mathrm{mmol} / 1$, or a fasting blood glucose reading of $\geq 7 \mathrm{mmol} / \mathrm{l}$ after the acute phase of stroke to exclude acute transient elevation of glucose as a stress response after stroke. ${ }^{21}$

Dyslipidaemia was defined as serum cholesterol of $>$ $5.2 \mathrm{mmol} / 1$ or high-density lipoprotein cholesterol (HDL-C) $<40 \mathrm{mg} / \mathrm{dl}(1.03 \mathrm{mmol} / \mathrm{l})$ for men and $<50$ $\mathrm{mg} / \mathrm{dl}(1.29 \mathrm{mmol} / \mathrm{l})$ for women or pre-stroke treatment with a cholesterol-lowering agent. ${ }^{22}$ Hypertriglyceridaemia was defined as a serum triglyceride levels $\geq$ $1.71 \mathrm{mmol} / 1$ according to the AHA/NHLBI criteria. ${ }^{23}$
Obesity was defined as a raised body mass index $>30$ $\mathrm{kg} / \mathrm{m}^{2}$ in ambulant patients or waist circumference of $>$ $80 \mathrm{~cm}$ in females and $>94 \mathrm{~cm}$ in males. ${ }^{24}$

Waist circumference was measured using a tape measure horizontally placed at the level of the superior crests and ensuring that the tape measure was snug and did not compress the skin. Measurement was made at the end of normal expiration. ${ }^{24}$ Current smoking status and alcohol intake statuses were ascertained from either the patient or a reliable relative. Current smokers were defined as those who smoked at least 10 cigarettes per day for 6 months or more and those who smoked daily for 1 year or more regardless of the number of cigarettes per day. A high alcohol intake was defined as $\geq 14$ units per week for women, $\geq 21$ units per week for men.

Congestive heart failure was defined clinically as a history of dyspnoea on minimal exertion, paroxysmal nocturnal dyspnoea or acute pulmonary oedema or the presence of distended neck veins (in other than the supine position and in the absence of venous obstruction), bilateral ankle oedema (not caused by a condition other than cardiac failure), hepatomegaly, crepitations in the absence of pulmonary disease, positive $S_{3}$, or chest radiographic evidence of pulmonary congestion (pleural fluid, pulmonary venous congestion, prominent pulmonary veins) with or without cardiomegaly. Previous stroke was defined as history of hospitalization for a syndrome of rapidly developing clinical signs of focal or global disturbance, attributed to ischaemic or haemorrhagic lesions in the brain with or without verification with computed tomography.

Physical activity status of participants was to be assessed using the International Physical Activity Questionnaire. However because some participants were either aphasic or unconscious their relatives were simply questioned on patients' physical activity status. Responders who reported spending more than half the day on their feet or that they were involved with daily exercise were classified as physically active. Those who spent less than half of the day on their feet or led a sedentary life were classed as physically inactive as has previously been applied. ${ }^{25}$

Serum uric acid levels were measured using an automated analyzer Cobas Integra 400 Plus (Roche) at the laboratory of department of chemical pathology at KATH. This laboratory is externally quality controlled. Hyperuricaemia was classified as elevated if levels are $>420 \mu \mathrm{mol} / 1$ in men and $>360 \mu \mathrm{mol} / 1$ in women taking into consideration patients on thiazide diuretics. The National Institute of Health Stroke Scale $(\mathrm{NIHSS})^{26}$ was employed to determine the severity of stroke within 24 hours of admission. 
Patient functional status on discharge was assessed using a modified Rankin Scale $(\mathrm{mRS})^{27}$ with scores ranging from 0 to 6 , with a score of 0 indicating no symptoms; a score of 5 indicating severe disability, confinement to bed, or incontinence; and a score of 6 indicating death. The clinical types of stroke were determined using cranial CT scans or clinically using the Siriraj Stroke Score ${ }^{28}$ when CT scan was not available.

\section{Statistical analyses}

The data from the questionnaire was entered into a Microsoft excel (2008) sheet and analysed with SPSS version 18. Univariate analyses of descriptive results of the demographic characteristics and identifiable risk factors were presented as percentages. The MannWhitney's U-test and the Student's t-test were used to compare medians and means respectively. Bivariable analyses to examine the associations between hyperuricaemia and the categorical variables were performed by constructing $2 \times 2$ contingency tables to determine odds ratios. Correlations between SUA concentration and continuous variables were also assessed by calculating either the Spearman's coefficient or the Pearson's coefficient for non-parametric and parametric data respectively.
Kaplan-Meier survival curves were constructed to examine associations between hyperuricaemia and stroke mortality. Duration of follow up was determined by subtracting the date of admission from the date of admission from the date of discharge or death of patient from hospital. A Cox proportional hazards regression model was used to model the individual and simultaneous effects of SUA concentrations and other baseline variables on in-patient survival after stroke. Interactions between covariates were tested by including multiplicative terms in regression models. In all cases, a 2tailed p-value less than 0.05 was considered significant.

\section{RESULTS}

Demographic characteristics and frequency of vascular risk factors for stroke: One hundred and fortyseven patients with stroke were recruited with a median (IQR) age of $65(52-72)$ years and a male: female ratio of 1.0: 1.2. The frequencies of hypertension, diabetes mellitus, obesity, hypercholesterolemia and physical inactivity were $87.8 \%, 29.3 \%, 58.1 \%, 50.4 \%$ and $76.9 \%$ as shown in table 1 .

Table 1.Uric acid concentration in relation to demographic characteristics and traditional risk factors of stroke

\begin{tabular}{|l|l|l|l|l|l|l|}
\hline Risk factor & $\begin{array}{l}\text { Frequency } \\
(\%)\end{array}$ & \multicolumn{2}{|l|}{$\begin{array}{l}\text { Mean } \pm \text { SD uric acid concentration accord- } \\
\text { ing to risk factor status }\end{array}$} & P value $^{\#}$ & $\begin{array}{l}\text { Odds } \\
\text { ratio }^{\infty}\end{array}$ & $95 \%$ CI \\
\hline & & Yes & No & & & \\
\hline Male sex & 46.3 & $457.1 \pm 230.9$ & $455.4 \pm 254.9$ & 0.97 & 1.25 & $0.65-2.39$ \\
\hline Hypertension & 87.8 & $457.4 \pm 231.3$ & $466.7 \pm 307.7$ & 0.88 & 1.85 & $0.65-5.23$ \\
\hline Diabetes mellitus & 29.3 & $508.6 \pm 287.8$ & $423.9 \pm 206.7$ & 0.04 & 1.28 & $0.65-2.49$ \\
\hline Obesity & 58.1 & $447.1 \pm 217.2$ & $475.5 \pm 265.2$ & 0.52 & 0.98 & $0.47-2.05$ \\
\hline Dyslipidaemia & 50.4 & $469.7 \pm 221.0$ & $439.0 \pm 234.3$ & 0.47 & 1.0 & $0.48-2.07$ \\
\hline Alcohol abuse & 21.8 & $443.8 \pm 198.6$ & $462.6 \pm 251.3$ & 0.70 & 0.98 & $0.46-2.08$ \\
\hline Physical inactivity & 76.9 & $461.3 \pm 249.9$ & $449.3 \pm 210.4$ & 0.80 & 0.82 & $0.38-1.77$ \\
\hline Cigarette smoking & 6.1 & $496.8 \pm 244.6$ & $458.0 \pm 240.8$ & 0.64 & 1.48 & $0.38-5.76$ \\
\hline Cardio-embolism & 2.7 & $493.3 \pm 280.6$ & $450.6 \pm 237.6$ & 0.76 & 3.60 & $0.37-35.44$ \\
\hline Previous stroke & 28.1 & $485.0 \pm 193.8$ & $446.8 \pm 242.6$ & 0.51 & 1.83 & $0.69-4.89$ \\
\hline
\end{tabular}

${ }^{*}$ Cardio-embolism includes 2 cases each of Atrial fibrillation and congestive cardiac failure

\#p-values refer to comparison in arithmetic means of serum uric acid concentration between those with risk factor and those without. Values are arithmetic means \pm standard deviation.

${ }^{\infty}$ Odds ratio with $95 \%$ confidence interval, no p-values provided.

\section{The frequency of hyperuricaemia among stroke pa-} tients

The mean \pm SEM of fasting serum uric acid concentration for stroke patients was $458.5 \pm 19.9 \mu \mathrm{mol} / 1$. The overall frequency of hyperuricaemia among stroke patients was $46.3 \%(\mathrm{n}=147)$. The frequency among males was $49.3 \%(\mathrm{n}=67)$ and among females was $43.8 \%$ $(\mathrm{n}=80)$. The number of stroke patients with hyperuricaemia increased with increasing age regardless of gender. Among 12 study participants on thiazide diuretics, 5 were hyperuricaemic while one out of twelve
(12) patients who were on Aspirin had hyperuricaemia. One patient had gout and was on daily allopurinol for control of symptoms.

\section{Associations between hyperuricaemia and the tradi- tional risk factors of stroke}

As shown in table 1 the serum uric acid concentration was significantly higher in diabetic patients than nondiabetics with $\mathrm{p}=0.04$. Additionally SUA was positively correlated with serum triglyceride concentration (spearman's $r=0.28, \mathrm{p}$-value of 0.003 ). The odds ratios testing associations between hyperuricaemia and the traditional risk factors of stroke are also shown on table 1 which reveals no significant association between these modifiable risk factors and SUA in stroke patients. 
Association between serum uric acid concentration and severity and types of stroke

There was a positive correlation between serum concentration of uric acid at presentation and severity of stroke assessed using the NIHSS, Pearson's $\mathrm{r}=0.25$, $p=0.003$. The difference in the mean \pm SEM serum uric acid concentration in ischaemic and haemorrhagic stroke types of $439.4 \pm 24.2 \mu \mathrm{mol} / 1$ vs $485.9 \pm 24.2$ $\mu \mathrm{mol} / 1, \mathrm{p}=0.30$ respectively was not significantly different.

Table 2 Cox proportional hazards multiple regression analysis of determinants of mortality in acute stroke in Kumasi.

\begin{tabular}{|c|c|c|c|c|}
\hline Variable & $\begin{array}{l}\text { Unadjusted HR } \\
(95 \% \mathrm{CI})\end{array}$ & $\begin{array}{l}\mathrm{P}- \\
\text { value }\end{array}$ & $\begin{array}{l}\text { Adjusted } \\
\text { HR }(95 \% \\
\text { CI })\end{array}$ & $\begin{array}{l}\mathrm{P}- \\
\text { value }\end{array}$ \\
\hline $\begin{array}{l}\text { Age (each } 10 \text { year } \\
\text { increase) }\end{array}$ & $1.01(0.84-1.21)$ & 0.89 & - & - \\
\hline $\begin{array}{l}\text { Gender } \\
\text { Male } \\
\text { Female } \\
\end{array}$ & $\begin{array}{l}1.37(0.81-2.31) \\
1.00\end{array}$ & 0.24 & - & - \\
\hline $\begin{array}{l}\text { Serum uric acid } \\
\text { (each 100 } \mu \mathrm{mol} / 1 \\
\text { increase) }\end{array}$ & $1.14(1.05-1.23)$ & 0.001 & $\begin{array}{l}1.65 \\
(1.142 .39) \\
\end{array}$ & 0.009 \\
\hline $\begin{array}{l}\text { NIHSS on admis- } \\
\text { sion (each } 5 \text { units } \\
\text { increase }\end{array}$ & $1.87(1.59-2.21)$ & 0.000 & $\begin{array}{l}2.72 \\
(1.893 .91)\end{array}$ & 0.000 \\
\hline SUA * NIHSS & & & $\begin{array}{l}0.99 \\
(0.991 .00) \\
\end{array}$ & 0.01 \\
\hline
\end{tabular}

SUA * NIHSS interaction terms between serum uric acid concentration and NIHSS on admission

\section{Association between hyperuricaemia and outcomes of stroke}

Fifty-eight (39.5\%) out of 147 patients died on admission. Among stroke survivors $(\mathrm{n}=89), 2.2 \%, 4.5 \%$, $9.0 \%, 13.5 \%, 31.5 \%$ and $34.8 \%$ had functional outcomes corresponding to mRS scores of $0,1,2,3,4$ and 5 respectively. As shown in figure 1, SUA concentrations on admission trended positively with poor functional outcomes of strokes with the mean ( \pm SEM) serum uric acid concentration among patients increasing progressively from $316.5 \pm 64.5$ to $547.8 \pm 38.3 \mu \mathrm{mol} / 1$ corresponding to modified Rankin Scale scores of 0 to 6 respectively.

The mean \pm SEM serum uric acid concentration of stroke survivors of $400.3 \pm 19.0 \mu \mathrm{mol} / 1$ was significantly lower than that of those who died on admission $547.8 \pm 38.3 \mu \mathrm{mol} / \mathrm{l}, \mathrm{p}$-value of 0.0002 . A logistic regression analysis showed a strong relationship between hyperuricaemia and early death after stroke with an odds ratio of $2.91 ; 95 \%$ confidence interval (CI) 1.47 5.78; $\mathrm{p}=0.002$.

This association was further confirmed on survival analysis shown in figure 2 where patients with elevated serum uric acid after a stroke had a hazard ratio of 2.33 $(95 \%$ CI $1.75-2.92, p=0.001)$ of early mortality compared with normouricaemic patients. The association between stroke mortality and hyperuricaemia was stronger in patients with ischaemic strokes in comparison with those with haemorrhagic strokes.

Indeed the hazard ratio of mortality among ischaemic stroke patients with hyperuricaemia was 4.72 (95\% CI $1.6-20.2, p=0.008)$ while that of those with haemorrhagic stroke was 1.44 (95\% CI $0.77-2.98, \mathrm{p}>0.05)$.

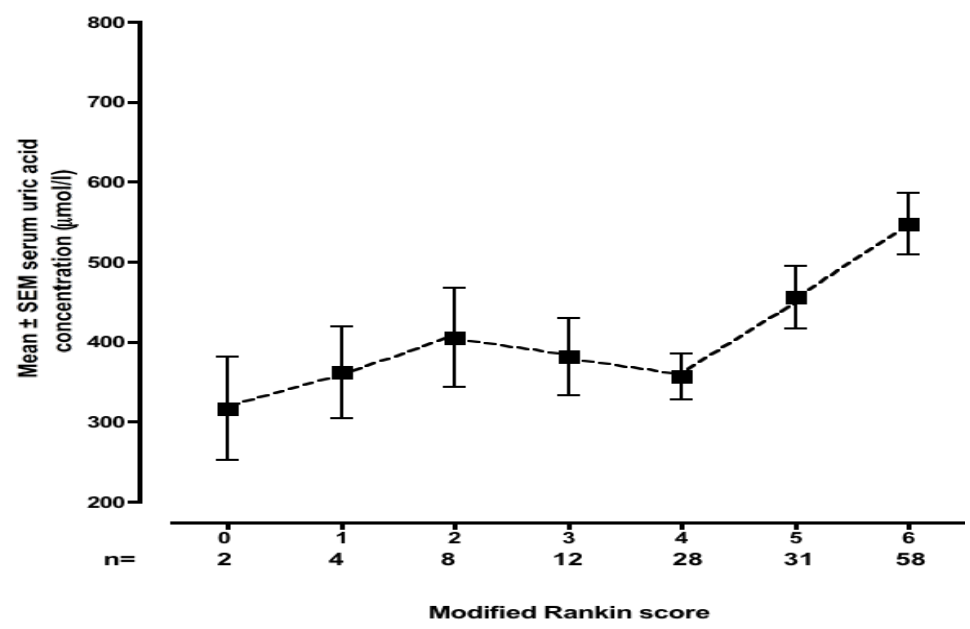

Figure 1 Serum uric acid and functional outcomes of stroke. Dose-response plot of the mean $( \pm$ standard error of mean) admission serum uric acid concentration and functional outcomes of stroke patients assessed using the modified Rankin scale.

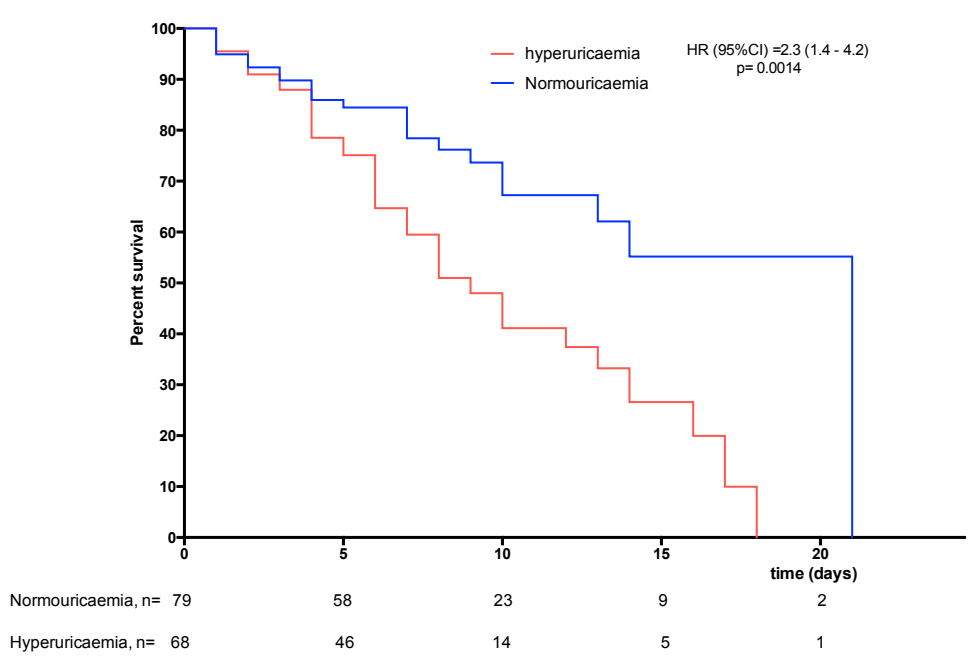

Figure 2 A graph showing a Kaplan - Meier survival plot of vital status of patients with normouricaemia compared with hyperuricaemia after a stroke. 
An independent association between increasing SUA concentration and mortality was noted in a Cox proportional hazards regression model, adjusted $\mathrm{HR}(95 \% \mathrm{CI})$ of 1.65 (1.14-2.39), $\mathrm{p}=0.009$ for each $100 \mu \mathrm{mol} / 1$ increase in SUA.

A significant interaction between severity of stroke and SUA on mortality was also observed in this model, shown in table 2 . As shown in figure 3, at concentrations below $300 \mu \mathrm{mol} / 1$ the case fatality rate was $27.5 \%$, gradually increasing to $28.9 \%$ between $300-$ $450 \mu \mathrm{mol} / 1$ and exponentially to $45.7 \%$ and $67.0 \%$ at concentration ranges of $450-600 \mu \mathrm{mol} / 1$ and above $601 \mu \mathrm{mol} / 1$ respectively.

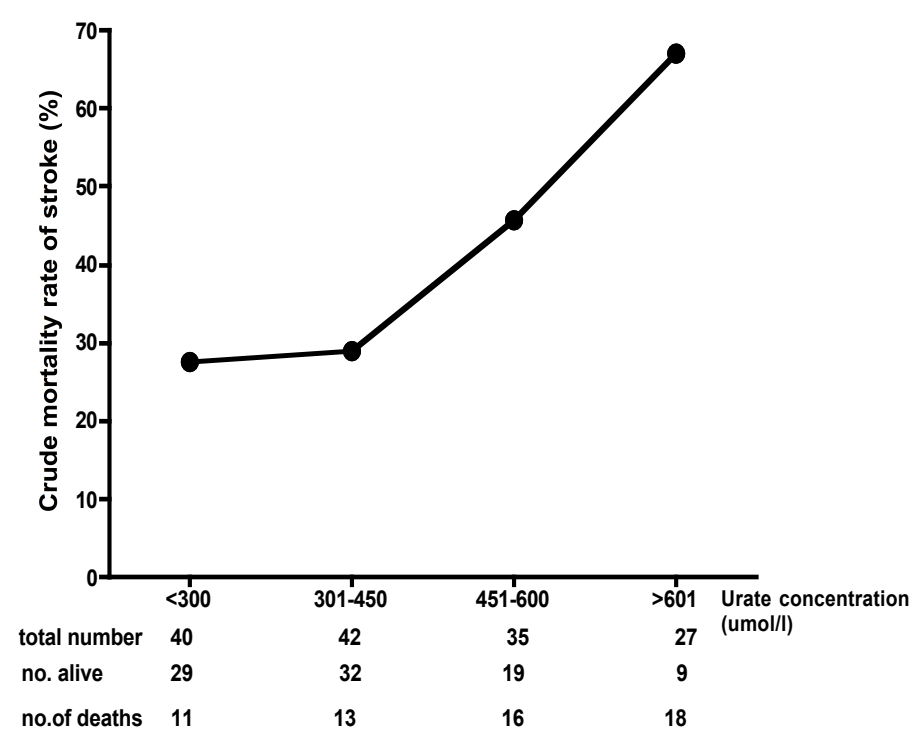

Figure 3 Serum uric acid and crude mortality rates of stroke.

Figure 3 shows a graph of dose - response relationship between serum uric acid concentrations and crude mortality rates in subjects with stroke. Crude mortality rate at each quartile of serum uric acid concentration was calculated by dividing the number of deaths by the total number of subjects at that quartile of serum uric acid.

\section{DISCUSSION}

The main observations in our study were as follows: there is a high frequency of hyperuricaemia (46.3\%) among Ghanaian stroke patients. Secondly the association between hyperuricaemia and the traditional risk factors among stroke patients was either weak or nonsignificant probably because of small sample size of the study. Thirdly there was a correlation between SUA and severity of stroke and an association between hyperuricaemia and poor functional outcomes. Most significantly, a potent dose-response association between stroke mortality and SUA was observed in this cohort. The findings from this observational prospec- tive study support the notion that SUA is an adverse prognostic marker and an indicator of the severity of stroke among Ghanaians.

Our findings are consistent with the body of scientific evidence. Among a cohort of Congolese patients, hyperuricaemia was found to be predictor of stroke and all cause mortality ${ }^{29}$. Karagiannis et al. found that elevated SUA was strongly associated with early death among 435 patients presenting with stroke at Thessaloniki, Greece $^{16}$. Weir and colleagues extended these findings in a study involving 3731 subjects, by noting that patients with elevated SUA concentrations measured 24 hours after the onset of stroke were more likely to have adverse outcomes such as death or placement in care. Additionally hyperuricaemia in these patients predicted the subsequent occurrence of vascular events such as ischaemic stroke, myocardial infarction, or vascular death 90 days after the stroke. ${ }^{15}$ We found an incremental trend between SUA and adverse functional outcomes among stroke survivors (figure 1) as well as stroke mortality (figures 2 and 3 ).

Regarding the association between stroke mortality and hyperuricaemia, we noted that the association was much stronger among patients presenting with ischaemic strokes- HR of 4.72 (95\% CI 1.6 - 20.2, $\mathrm{p}=0.008)$ - than hemorrhagic strokes - $1.44(95 \% \mathrm{CI}$ $0.77-2.98)$. Indeed a large prospective cohort study involving 41,879 men and 48,514 women aged $>35$ years conducted in Taiwan with a mean follow-up of 8.2 years corroborated this association between hyperuricaemia and adverse outcomes after ischaemic stroke with a hazard ratio of $1.35(\mathrm{p}<0.02) .{ }^{30}$

These findings together with those from this study suggest that hyperuricaemia in the setting of stroke carries a strong risk of an adverse outcome and may be neurotoxic as suggested by the worse neurological functional outcomes (figure 1). A direct mechanistic role for hyperuricaemia in atherogenesis and the clinical course of cerebrovascular disease has been suggested by the links between elevated uric acid and increased production of oxygen free radicals ${ }^{31}$, accelerated oxygenation of low-density lipoproteins which facilitates lipid peroxidation ${ }^{4}$, impairment of nitric oxide production with subsequent activation of the renin-angiotensin system $^{32}$, induction of endothelial dysfunction and smooth muscle cell proliferation. ${ }^{5,33}$

Furthermore, uric acid has been found in rats to stimulate the synthesis of monocyte chemoattractant protein1 by vascular smooth muscle cells ${ }^{6}$, which is known to have a key role in stimulating macrophage infiltration in atherosclerotic vessels. ${ }^{34}$ 
Finally, hyperuricaemia increases platelet adhesiveness and aggregation. ${ }^{31}$ All these factors are important for the development and progression of atherosclerosis and may explain the especially strong association between uric acid and carotid atherosclerosis, a well-known risk factor for stroke. 2,35

In spite of these compelling lines of evidence from epidemiological and experimental studies, a few wellconducted human clinical studies have produced contradictory findings. Chamorro et al for instance measured SUA concentrations among 881 consecutive ischaemic stroke patients at the onset of ischaemic symptoms and found an inverse correlation between SUA and early neurologic impairment and final infarction size on computed tomography or magnetic resonance imaging with a positive association between increasing SUA concentration and good clinical outcomes. ${ }^{17}$ In another intriguing study, Brouns et al followed the kinetics of SUA on admission and at 24 hours, 72 hours, day 7, month 1 and month 3 after a stroke in 199 patients and demonstrated that a significant decline in serum uric acid concentrations occurred within the first week after a stroke and this decrease correlated with more severe stroke, unfavourable stroke evolution, and poor long-term stroke outcome. ${ }^{36}$ These findings support an opposing school of thought that a high concentration of SUA could be neuroprotective and has antioxidant properties in the setting of an acute stroke.

Muir et al have demonstrated in a pilot randomised double-blinded study that the administration of $300 \mathrm{mg}$ of the hypouricosuric agent, allopurinol for 6 weeks produced significant reductions in serum intercellular adhesion molecule (ICAM) concentrations compared with a lower dose of $100 \mathrm{mg}$ of allopurinol or a placebo $^{37}$. Serum ICAM is a pro-inflammatory molecule which serves as a surrogate marker of vascular and metabolic health. Thus further studies are needed to determine whether reductions in SUA after stroke may have beneficial clinical effects.

A limitation of this study is that only 19 out of 147 (13\%) had cranial CT scans to confirm and type strokes at presentation. Thus clinical types of stroke were determined using the Siriraj stroke scale.

\section{CONCLUSION}

This study has identified a high frequency of hyperuricaemia among Ghanaian patients presenting with stroke. Hyperuricaemia among stroke patients is strongly associated with worse functional outcomes after an acute stroke.

\section{ACKNOWLEDGEMENTS}

Personal acknowledgements: We are grateful to all house officers and nurses involved in the care of study participants.

\section{REFERENCES}

1. Lehto S, Niskanen L, Rönnemaa T, Laakso M: Serum uric acid is a strong predictor of stroke in patients with Non- insulin dependent diabetes mellitus. Stroke. 1998, 29(3): 635 -639.

2. Nieto FJ, Iribarren C, Gross MD, Comstock GW, Cutler RG: Uric acid and serum antioxidant capacity: A reaction to atherosclerosis? Atherosclerosis. 2000, 148(1): 131-139.

3. Bagnati M, Perugini C, Cau C, Bordone R, Albano E, Bellomo G: When and why a water- soluble antioxidant becomes pro-oxidant during copperinduced low-density lipoprotein oxidation: a study using uric acid. Biochem J. 1999, 340: 143-152.

4. Schlotte V, Sevanian A, Hochstein P, Weithmann KU: Effect of uric acid and chemical analogues on oxidation of human low-density lipoprotein in vitro. Free Radic Biol Med. 1998, 25: 839-847.

5. Rao GN, Corson MA, Berk BC: Uric acid stimulates vascular smooth muscle proliferation by increasing platelet-derived growth factor A-chain expression. J Biol Chem. 1991, 266:8604-8608.

6. Kanellis J, Watanabe S, Li JH, Kang DH, Li P, Nakagawa T, Wamsley A, Sheikh-Hamad D, Lan HY, Feng L, Johnson RJ: Uric acid stimulates monocyte chemoattractant protein-1 production in vascular smooth muscle cells via mitogenactivated protein kinase and cyclooxygenase-2. Hypertension. 2003, 41:1287-1293.

7. Lee J, Sparrow D, Vokonas PS, Landsberg L, Weiss ST: Uric acid and coronary heart disease risk: evidence for a role of uric acid in the obesityinsulin resistance syndrome: the Normative Aging Study. Am J Epidemiol. 1995, 142: 288 -294.

8. Selby JV, Friedman GD, Quessenberry CPJ: Precursors of essential hypertension: pulmonary function, heart rate, uric acid, serum cholesterol, and other serum chemistries. Am J Epidemiol. 1990, 131: $1017-1027$.

9. Wilson PWF, Garrison RJ, Abbott RD, Castelli WB: Factors associated with lipoprotein cholesterol levels: the Framingham Study. Arteriosclerosis. 1983, 3: 273-281.

10. Zavaroni I, Mazza S, Fantuzzi M, Dall’Anglio E, Bonora E, Delsignore R, Passeri M, Reaven GM: Changes in insulin and lipid metabolism in males with asymptomatic hyperuricaemia. Int $\mathrm{J} \mathrm{Med.}$ 1993, 234:25-30. 
11. Modan M, Halkin H, Karasik A, Lusky A: Elevated serum uric acid: a facet of hyperinsulinemia. Diabetologia. 1987, 30:713-718.

12. Facchini F, Chen YDI, Hollenbeck CB, Reaven GM: Relationship between resistance to insulinmediated glucose uptake, urinary uric acid clearance, and plasma uric acid concentration. JAMA. 1991, 266: 3008-3011.

13. Milionis HJ, Kalantzi KJ, Goudevemos JA, Seferiadis K, Mikhailidis DP, Elisaf MS: Serum uric acid levels and risk for acute ischaemic nonembolic stroke in elderly subjects. J Intern Med. 2005, 258: 435-441.

14. Daskalopoulou SS, Athyros VG, Elisaf M, Mikhailidis D: The impact of serum uric acid on cardiovascular outcomes in the LIFE study. Kidney Int. 2004, 66: 1714-1715.

15. Weir CJ, Muir SW, Walters MR, Lees KR: Serum urate as an independent predictor of poor outcome and future vascular events after acute stroke. Stroke. 2003, 34: 1951-1956.

16. Karagiannis A, Mikhailidis DP, Tziomalos K, Sileili M, Savvatianos S, Kakafika A, Gossios T, Krikis N, Moschou I, Xochellis M, Athyros VG: Serum uric acid as an independent predictor of early death after acute stroke. Circ J. 2007, 71: 11201127.

17. Chamorro A, Obach V, Cervera A, Revilla M, Deulofeu R, Aponte JH: Prognostic significance of uric acid concentration in patients with acute ischaemic stroke. Stroke. 2002, 33(4): 1048-1052.

18. Kim SY, Guevara JP, Kim KM, Choi HK, Heitjan DF, Albert DA: Hyperuricaemia and risk of stroke: a systematic review and meta-analysis. Arthritis Rheum. 2009, 61(7):885-892.

19. Connor MD, Walker R, Modi G, Warlow CP: Burden of stroke in black populations in subSaharan Africa. Lancet Neurol. 2007, 6(3):269278.

20. Whitworth JA, for the World Health Organisation, International Society of Hypertension Writing Group. 2003 World Health Organisation (WHO)/ International Society of Hypertension (ISH) statement on management of hypertension. J Hypertens. 2003, 21:1983-1992.

21. Alberti KG, Zimmet PZ. Definition, diagnosis and classification of diabetes mellitus and its complications, part 1: diagnosis and classification of diabetes mellitus provisional report of a WHO consultation. Diabet Med. 1998, 15: 539 -553.

22. Strategies for the prevention of coronary heart disease: a policy statement of the European Atherosclerosis Society. Eur Heart J. 1987, 8: 77-88.

23. Grundy SM, Cleeman JI, Daniels SR, Donato KA, Eckel RH, Franklin BA, Gordon DJ, Krauss RM, Savage PJ, Smith SC Jr, Spertus JA, Costa F,
American Heart Association, National Heart, Lung, and Blood Institute: Diagnosis and management of the metabolic syndrome: an American Heart Association/ National Heart, Lung, and Blood Institute statement. Circulation. 2005, 112 (17): 2735-2752.

24. World Health Organisation: Obesity: Preventing and Managing the Global Epidemic. Report on a WHO consultation on Obesity. 1998.

25. Van der Sande MAB, Walraven GEL, Milligan PJM, Banya WAS, Ceesay SM, Nyan OA, McAdam KPWJ: Family history: an opportunity for early interventions and improved control of hypertension, obesity and diabetes. Bulletin of the World Health Organisation. 2001, 79: 321-328.

26. Brott $\mathrm{T}$, Adama HP, Olinger CP, Marler JR, Barsan WG, Biller J, Spilker J, Holleran R, Eberle R, Hertzberg V, Rorick M, Moowaw CJ, Walker M: Measurement of acute cerebral infarction: a clinical examination scale. Stroke. 1989, 20:864870 .

27. UK-TIA Study Group: The UK-TIA aspirin trial: Interim results. $\mathrm{Br}$ Med $J$. 1988; 296:316-320.

28. Poungvarin N, Viriyavejakul A, Komontri C. Siriraj stroke score and validation study to distinguish supratentorial intracerebral haemorrhage from infarction. BMJ. 1991; 302:1565-1567.

29. Longo-Mbenza B, Lulla EL, Mbete P, Vita EK. Is hyperuricaemia a risk factor for stroke and coronary heart disease among Africans? Int J Cardiol. 1999;71(1):17-22.

30. Chen JH, Chuang SY, Chen HJ, Yeh WT, Pan WH: Serum uric acid as an independent risk factor for all-cause, cardiovascular, and ischaemic stroke mortality: a Chinese cohort study. Arthritis Rheum. 2009, 61(2):225- 232.

31. Johnson RJ, Kang DH, Feig D, Kivilghn S, Kanellis J, Watanabe S, Tuttle KR, Rodriguez-Iturbe B, Herrera-Acosta J, Mazzali M: Is there a pathogenetic role for uric acid in hypertension and cardiovascular and renal disease? Hypertension. 2003, 41: 1183-1190.

32. Eslami P, Corry DB, Nyby MD, Tuck ML: Inhibition of oxidative stress and improvement of nitric oxide production by ACE inhibitors and the AT1 receptor blockers in uric acid stimulated vascular smooth muscle cells. Am J Hypertens. 2004, 17(suppl 1):S154-S155.

33. Khosla UM, Zharikov S, Finch JL, Nakagawa T, Roncal C, Mu W, Krotova K, Block ER, Prabhakar S, Johnson RJ: Hyperuricaemia induces endothelial dysfunction. Kidney Int. 2005; 67(5): 1739-1742.

34. Gu L, Okada Y, Clinton SK, Gerard C, Sukhova GK, Libby P, Rollins BJ: Absence of monocyte chemoattractant protein-1 reduces atherosclerosis 
in low-density lipoprotein receptor deficient mice. Mol Cell. 1998, 2:275-281.

35. Crouse JR, Toole JF, McKinney WM, Dignan MB, Howard G, Kahl FR, McMahan MR, Harpold $\mathrm{GH}$ : Risk factors for extracranial carotid artery atherosclerosis. Stroke. 1987,18:990-996.

36. Brouns R, Walters A, Van De Vijver G, De Surgeloose D, Sheorajpanday R, De Deyn PP: Decrease in uric acid in acute ischaemic stroke correlates with stroke severity, evolution and outcome. Clin Chem Lab Med. 2010, 48(3):383-390.

37. Muir SW, Harrow C, Dawson J, Lees KR, Weir CJ, Sattar N, Walters MR: Allopurinol use yields potentially beneficial effects on inflammatory indices in those with recent ischaemic stroke: A randomised, double-blind, placebo-controlled trial. Stroke. 2008, 39:3303-3307. 